The East African Medical Journal Vol. 81 No. 1 January 2004

DIETARY SELENIUM AND COPPER INTAKE BY RESIDENT UNDERGRADUATE STUDENTS OF THE UNIVERSITY OF GHANA

E. E. K., Takyi, B.Sc., M.Sc., M.Phil. Ph.D., Senior Research Fellow and Head, Nutrition Unit, Noguchi Memorial Institute for Medical Research, University of Ghana and P. Amankwa, B.Sc Department of Nutrition, University of Ghana

Request for reprints to: Dr. E. E. K., Takyi, B.Sc, M.Sc., M.Phil., Ph.D NMIMR University of Ghana P.O. Box LG. 581 Legon, Ghana

\title{
DIETARY SELENIUM AND COPPER INTAKE BY RESIDENT UNDERGRADUATE STUDENTS OF THE UNIVERSITY OF GHANA
}

\section{E. E. K. TAKYI and P. AMANKWA}

\begin{abstract}
Objectives: To determine and evaluate dietary intake of selenium and copper by resident undergraduate students of the University of Ghana.

Design: Prospective/comparative study.

Setting: The university of Ghana, Legon, Accra.

Subject: One hundred and fifty undergraduate resident students in five out of seven halls of residence of the University of Ghana.

Main outcome measures: Pre-tested structure questionnaires were administered to informed students to obtain personal data, intake of selenium, copper and/or multimineral supplements and foods consumed as well as frequency of consumption, A twenty four hour food intake on two non-consecutive days, were used to determine food intake. Selenium and copper levels in the foods identified were determined using Atomic Absorption Spectrophotometer (AAS) and compared to the respective RDAs to assess intake adequacy/inadequacy.

Results: None of the students interviewed took in selenium or copper supplements, although $2 \%$ took in multi-mineral supplements, which contained insignificant levels of selenium and/or copper. In the case of copper, $7.3 \%$ (11/150) met $75-100 \%$ of the RDA, while $1.3 \%(2 / 150)$ met the RDA in the case of selenium. As many as $15.3 \%$ $(23 / 150$; in the case of copper) and $83 \%(123 / 150$; in the case of selenium) did not meet the required intakes. However, $77 \%$ (116/150) had excess intake of copper while $15.7 \%$ $(25 / 150)$ took excess selenium

Conclusion: Due to the importance of these micronutrients and in the face of poor nutritional status, as judged by the few that met the required RDAs as well as excess, there is a need to carry out blood analyses to determine whether the dietary pattern has been translated systemically. If indicated, the University authorities must consider mounting nutritional education to ensure that those deficient take in the required levels while those consuming excess are made to cut down on their intakes, since both deficient and excess status have physiological consequences.
\end{abstract}

\section{INTRODUCTION}

Selenium and Copper are among the fourteen or so essential human elements commonly referred to as trace elements or micronutrients. They are termed trace elements (micronutrients) because they are present in animal tissues at concentration of less than $0.005 \%$ body weight or for the fact that their requirements in humans and animals are less than 100mg/day(1,2).

These trace elements act as catalysts in a variety of enzyme systems. In this respect, their roles range from weak ionic enzymatic cofactors to highly specific metalloenzymes(3). The trace elements function in the enzymes by direct participation in catalysis, combination with substrate to form a complex upon which the enzyme acts, formation of metalloenzymes, which bind with the substrate, combination with a reaction product and/or maintaining the quaternary structure of the enzymes(4).
Humans and animals require Selenium for a number of Selenium-dependent enzymes known as Selenoproteins. At least eleven selenoproteins have been characterised and there is evidence that additional selenoproteins exist(5).

Copper is also a critical functional component of a number of essential enzymes known as coproenzymes including, cytochrome oxidase, Lysyl oxidase, ceruloplasmin, Dopamine-B-monooxygenase, monoamine oxidase and tyrosinase. Physiologically, selenium is an important part of antioxidant enzymes that protect cells against the effects of free radicals produced during normal metabolism. It is also essential for normal functioning of the immune system and thyroid gland(57). Copper is also a critical functioning component of the cuproproteins which are involved in energy production, connection tissue formation, iron metabolism, neurotransmitter synthesis and metabolism, functioning and maintenances of myelin, melanin formation, 
participation as an antioxidant and regulation of gene expression $(8,9)$. In the body copper shifts between the cuprous $\left(\mathrm{cu}^{+1}\right)$ and the cupric $\left(\mathrm{Cu}^{+2}\right)$ states and its ability to accept and donate electrons explains its important role in the oxidation - reduction and in the scavenging of free radical(10).

Since these trace elements are indispensable to life, this study was carried out to determine and evaluate their intake in resident students of the university of Ghana.

\section{MATERIALS AND METHODS}

Study Population: The undergraduate resident students of the University of Ghana were used. Informed consent was obtained from each participant. Students were randomly selected from five (out of 7) halls of residence, based on student population in each hall. The other two halls were left out since they were new halls whose administration was not fully established to allow enrollment of students for the study. Their age ranged from 19 to 38 years.

Sample size determination: Using a $95 \%$ confidence level, an alpha level of 0.05 and assuming that $10 \%$ of the population in this study were selenium and copper deficient, sample size of 135 students was obtained. Allowing a $10 \%$ drop out, 150 students were assessed. Out of this $62 \%$ (92) males and $39 \%$ (58) females were selected to reflect the ratio of male to female undergraduate resident students in the university.

Study design: This was a cross-sectional study involving 150 resident undergraduate resident students of the University of Ghana. It was based on pre-tested, structured semiquantitative questionnaires and laboratory analyses. The questionnaires were in two parts: personal data and dietary data. The personal data sought to gather information on the student's general health. Questions asked were also geared to providing answers that indicated whether students have a disease condition that requires taking in copper and/or selenium supplement or drugs that supply these micronutrients.

The dietary questionnaires (Food frequency questionnaires, FFQ) sought to gather information on the frequency at which particular foods were eaten. The twenty four hour questionnaires sought to gather information on the amount of foods that were identified in the FFQs, were consumed. This part provided information for the determination of the percentage of Recommended Daily Allowance (RDA) of selenium and copper met by each student.

The twenty four hour food intake was conducted on two non-consecutive days. One of these days was a weekday, the other a weekend. Home available measures, models and weighing scales were used to determine the amount of food intake. Details of the methods had been reported earlier(11)

Representations of the foods identified in the twenty four hour questionnaires and FFQs were purchased from the same sources from which students got their supplies and analysed for selenium and copper levels. These analysis became necessary since selenium and copper concentrations of the foodstuffs were not available in the food composition tables used in Ghana.

Laboratory analysis: Two (2) g of each food sample were ashed at $600^{\circ} \mathrm{C}$ for five hours in a muffle furnace. The ash was dissolved in $10 \%$ hydrochloric acid and the volume made up to $10 \mathrm{ml}$ in an acid washed volumetric flask. The selenium and copper concentrations were determined from the digest using the Atomic Absorption Spectrophotometer. Standard solutions of copper or selenium were prepared $(0.1$, $0.5,1.5,2.5,5$, and $10 \mu \mathrm{g} / \mathrm{mL}$ ) in $10 \%$ hydrochloric acid, and run concurrently. The concentration of selenium and copper were obtained from the line of best fit of the standard curves.

Data analysis: Microsoft Excel statistical package was used to analyse the data. A cutoff point of $75 \%$ of the Recommended Daily Allowance (RDA) for copper and selenium was used to indicate adequate or inadequate intakes. Bar charts were drawn using Excel Statistical package. $F$ values having $\mathrm{p}<0.05$ were regarded as significant, while p> 0.05 were regarded as not significant.

\section{RESULTS}

Personal Data: Table 1 shows the age distribution of the students used in the study. Majority of the students $(84 \% ; 126 / 150)$ fell within the ages of $20-26$ years, with a peak at 22 years; $6.0 \%$ were 19 years and $10.0 \%$ were aged 27-38 years old.

Students Intake of Supplements: Table 2 indicated that none of the students took neat supplements of either selenium or copper. Small proportion of $2 \%$ took multimineral supplements that contained selenium and copper. However, their intakes were insignificant compared to the respective RDAs. It can therefore be deduced that the only sources of selenium and copper were the foods consumed.

None of the students interviewed took in Penicillamine (an antagonist of copper absorption) and an insignificant percentage admitted taking in some antacid sometime during the semester prior to the time of the study. Both of these drugs are known to affect the absorption and utilisation of copper (12).

Food intake: The different types of foods eaten as well as their contributions to the respective RDAs for copper and selenium are shown in figures 1 and 2 respectively. Tables 3 (for copper) and 4 (for selenium) also show the breakdown of the RDAs to indicate the various percentages met.

Table 1

Age distribution of the study population

\begin{tabular}{lc}
\hline Age (years) & Frequency \\
\hline 19 & $9(6.0 \%)$ \\
20 & $25(16.7 \%)$ \\
21 & $16(10.7 \%)$ \\
22 & $33(22.0 \%)$ \\
23 & $27(18.0 \%)$ \\
$24-26$ & $25(16.7 \%)$ \\
27 & $6(4.0 \%)$ \\
$28-38$ & $9(6.0 \%)$ \\
\hline
\end{tabular}




\section{Figure 1}

Percentage RDA of copper met by a student from the different food samples

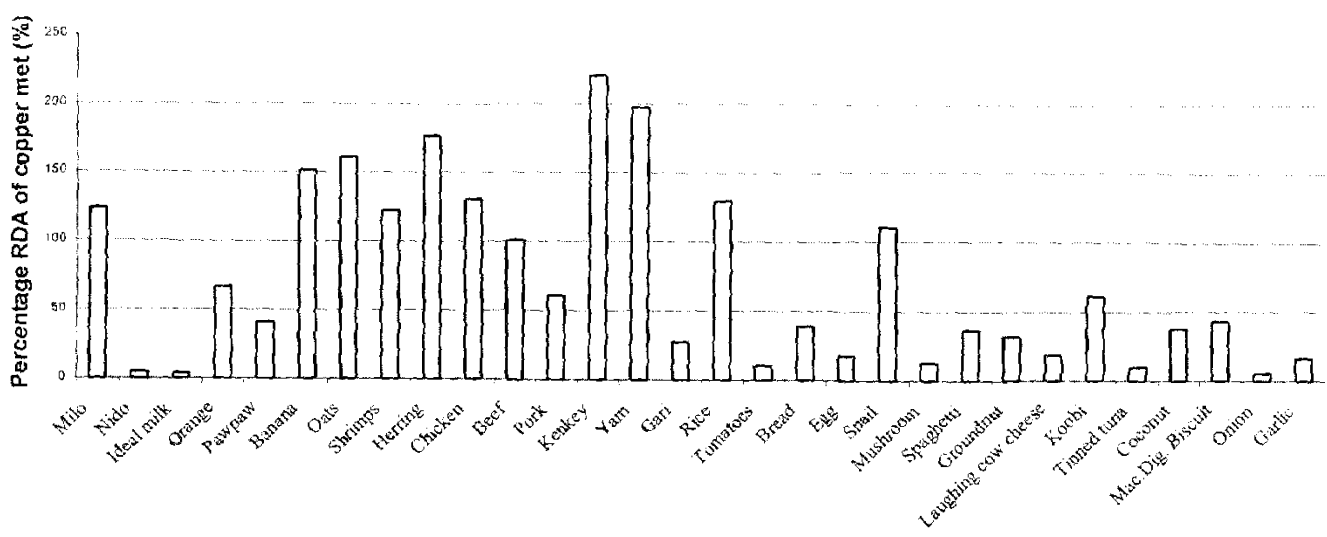

Food sample

Figure 2

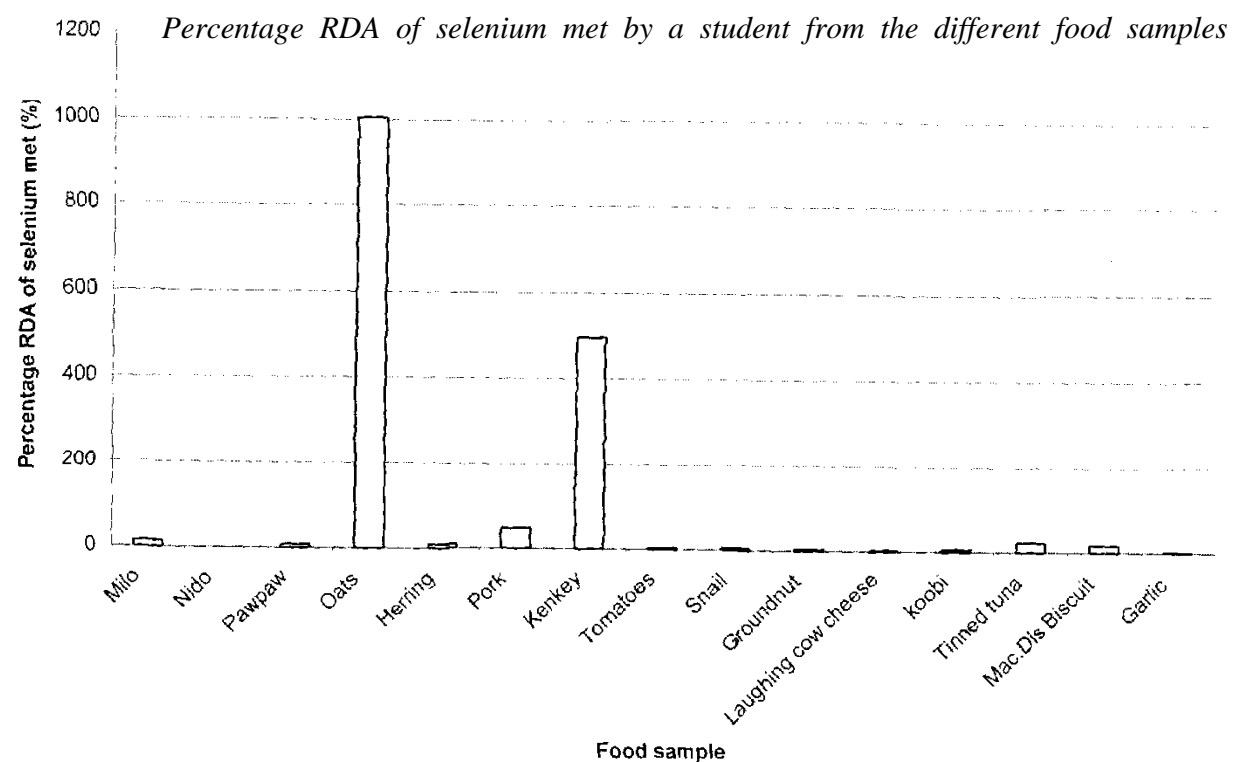

Table 2

Student's intake of Selenium, Copper and Mineral Supplements

\begin{tabular}{lll}
\hline Status & $\begin{array}{l}\text { Students taking } \\
\text { Supplements }\end{array}$ & $\begin{array}{l}\text { Students taking no } \\
\text { supplements }\end{array}$ \\
\hline & & \\
Selenium supplements & $0(0 \%)$ & $150(100 \%)$ \\
Copper supplement & $0(0 \%)$ & $150(100 \%)$ \\
$\begin{array}{l}\text { Multi-mineral } \\
\text { containing selenium }\end{array}$ & $3(2 \%)$ & $147(98 \%)$ \\
or copper & & \\
\hline
\end{tabular}

RDA for Selenium: Men and women $(19+$ years=55 $\mu \mathrm{g} / \mathrm{day}$; Pregnant women, 60 and Lactating women= 70 (13). RDA for copper $=900 \mu \mathrm{g}$ for adult men and women aged $19+(14)$
Table 3

Percentage RDA of copper met by students

\begin{tabular}{llllll}
\hline Sex & $0-20 \%$ & $21-50 \%$ & $51-74 \%$ & $75-100 \%$ & $>100 \%$ \\
\hline Male (92) & $2(23)$ & $6(6.5)$ & $7(8)$ & $10(11)$ & $67(51.5)$ \\
Female (58) & $3(5.2)$ & $5(8.6)$ & $0(0)$ & $1(1.7)$ & $49(84.5)$ \\
\hline & & & & & \\
Total (150) & $5(3.3 \%)$ & $11(7.3 \%)$ & $7(4.7 \%)$ & $11(7.3 \%)$ & $116(77.4 \%)$
\end{tabular}

RDA for copper $=900 \mu \mathrm{g}$ for adult men and women, aged $19+(14)$ 
Table 4

Percentage RDA of selenium met by students

\begin{tabular}{lllllr}
\hline Sex & $0-20 \%$ & $21-50 \%$ & $51-74 \%$ & $75-100 \%$ & $>100 \%$ \\
\hline Male (92) & $62(67)$ & $5(5)$ & $2(2.5)$ & $2(2.5)$ & $21(23)$ \\
Female(58) & $50(86)$ & $2(3.4)$ & $2(3.4)$ & $0(0)$ & $4(7.2)$ \\
\hline Total (150) & $112(75)$ & $7(5)$ & $4(3.0)$ & $2(1.3)$ & $25(15.7)$
\end{tabular}

RDA for Selenium: Men and women $(19+$ years $=55 \mu \mathrm{g}$; pregnant women $=60$ and lactating women $=70 \mu \mathrm{g}(13)$

Table 5

Frequency at which the students ate analysed foods

\begin{tabular}{|c|c|c|c|c|}
\hline Food sample & $>1 / \mathrm{D}$ & $1 / \mathrm{D}$ & $3-6 / W$ & $\mathrm{~N}$ \\
\hline Milo & 29 & 59 & 36 & 11 \\
\hline Nido & 23 & 53 & 50 & 20 \\
\hline Ideal milk & 3 & 24 & 37 & 35 \\
\hline Orange & 6 & 38 & 68 & 8 \\
\hline Pawpaw & 3 & 4 & 24 & 56 \\
\hline Banana & 7 & 17 & 68 & 16 \\
\hline Oats & 1 & 1 & 18 & 69 \\
\hline Shrimp & 1 & 6 & 33 & 67 \\
\hline Herring & 0 & 14 & 40 & 51 \\
\hline Chicken & 6 & 13 & 66 & 16 \\
\hline Beef & 3 & 15 & 50 & 41 \\
\hline Pork & 1 & 0 & 17 & 95 \\
\hline Kenkey & 3 & 23 & 74 & 13 \\
\hline Yam & 3 & 10 & 59 & 15 \\
\hline Gari & 1 & 9 & 47 & 26 \\
\hline Rice & 37 & 51 & 59 & 0 \\
\hline Tomatoes & 59 & 66 & 20 & 0 \\
\hline Bread & 37 & 68 & 39 & 0 \\
\hline Egg & 11 & 11 & 86 & 8 \\
\hline Snail & 0 & 0 & 6 & 98 \\
\hline Mushroom & 0 & 0 & 0 & 124 \\
\hline Spaghetti & 6 & 6 & 63 & 35 \\
\hline Groundnut & 6 & 8 & 66 & 16 \\
\hline $\begin{array}{l}\text { Laughing cow } \\
\text { cheese }\end{array}$ & 1 & 9 & 25 & 58 \\
\hline $\begin{array}{l}\text { 'koobi' (salted } \\
\text { dried Tilapia) }\end{array}$ & 0 & 0 & 9 & 82 \\
\hline Tinned Tuna & 0 & 17 & 52 & 33 \\
\hline Coconut & 0 & 0 & 30 & 44 \\
\hline Macvites & 0 & 1 & 31 & 53 \\
\hline \multicolumn{5}{|l|}{ Digestive } \\
\hline \multicolumn{5}{|l|}{ Biscuit } \\
\hline Onion & 73 & 46 & 17 & 9 \\
\hline Garlic & 17 & 16 & 14 & 74 \\
\hline
\end{tabular}

$>\mathrm{I} / \mathrm{D}=$ consumption is more than once per day; $1 / \mathrm{D}=$ Consumption is once per day, $3-6 / \mathrm{W}=$ consumption is $3-6$ times in a week; $\mathrm{N}=$ foods never consumed or seldomly consumed. The smaller sample size of 150 indicated that not all students responded to the FFQs.
From figure 1 , the percentage of RDA met for copper ranged from 3\% (garlic) to $265 \%$ (Herrings). Apart from herrings which gave the highest value of $265 \%$, values for plant materials on the whole were higher than animal products; eg. Kenkey, a fermented corn dough product, had a value of $263 \%$, rice, $207 \%$; oats $222 \%$, as compared to animal products such as tinned tuna, egg, pork and shrimps with values of 10 , 18,81 and $157 \%$ respectively. These figures meant that when diets are well blended in their preparation, it should be possible to meet adequate copper status. It is well known that mineral composition of foods/fodder depends on the soil in which the plants were grown as well as the cultivars of crops. Since animals are usually feed on grass, it is logical to conclude that the level of copper in animal products will depend on the levels found in the animal fodder.

Table 3 indicates that $7.3 \%$ (11/ 150) of students assessed met their required copper intake by meeting $75-100 \%$ of RDA for copper. $15.3 \%$ (116/150) had excess intake clinically evident or frank copper deficiency is relatively rare. Serum copper levels and ceruloplasmin levels may fall to $30 \%$ of the normal value in cases of severe copper deficiency. One of the most common clinical signs of copper deficiency is an anemia that is unresponsive to iron therapy, but corrected by copper supplements. Anemia is the result of defective iron mobilisation due to decreased ceruloplasmin activity(12).

\section{DISCUSSIONS}

Copper deficiency may also result in neutroperia (low levels of neutrophils), a condition accompanied by increased susceptibility to infections. Other conditions include osteoporosis in low birth weight infants and young children. Less common features of copper deficiency include loss of pigmentation, neurolological and impaired growth(15). Individuals at risk of copper deficiency include premature babies, individuals with malabsorption syndrome including celiac disease, sprue and short bowel syndrome due to surgical removal of a large portion of the intestine(15). Copper toxicity is also rare.

Acute copper poisoning can occur with the contamination of beverage in copper containing containers as well as from contaminated water supply(16). Symptoms include abdominal pains, nausea, vomiting and diarrhoea, which help prevent additional ingestion and absorption of copper. More serious syndromes of acute copper toxicity include severe liver damage, kidney failure, coma and death.

Due to the fact that only $11.7 \%$ of the subjects took in the required amounts of copper, with $15.3 \%$ deficient while $77.4 \%$ took excess, there is the need to carry out serum analysis in these students to determine whether the deficiency pattern has been translated systemically. 
Figure 2 and table 3 depict the selenium intake by the students. Fourteen out of 30 food samples also did not contain any selenium and hence supplied $0 \%$ RDA. The remaining 16 samples that contributed to the meeting RDA are shown in figure 2 . The values ranged from $0.39 \%$ RDA $(1.20 \mu \mathrm{g} / 100 \mathrm{~g})$ for Nido milk powder to $622 \%$ RDA $(216.57 \mu \mathrm{g} / 100 \mathrm{~g})$ for oats. Oats had the highest levels, followed by kenkey. All other foods have selenium concentrations lower than Selenium RDA of $55 \mu \mathrm{g} / 100 \mathrm{~g}$.

Only $1.3 \%(2 / 150)$ students met the recommended RDA for Selenium with as many as $83 \%$ (123/150) deficient while $15.7 \%(25 / 150)$ had excess intake of $>100 \%$ (Table 4). Selenium is found in a wide variety of foods, particularly, seafoods, most cereals, vegetables, chicken, beef and pork (17). However since it is not essential for plant growth, the levels found in foods of plant origin depends on the soil composition in which the crop was grown as well as the cultivars grown. In fact studies have shown that selenium content of cereal crops between countries or even between regions can vary as much as one thousand fold. This has been compounded by extensive use of agrochemicals, which with acid rain tends to wash any remaining traces of selenium out of the soil .As a result, livestock that graze on these selenium-poor pastures are invariably low in the trace element. This means that not only are the meat low in selenium but other animal products such as milk and eggs are affected(17).

Food processing further depletes Selenium for example, brown rice has 15 times Selenium as white rice. Selenium deficiency is most common in areas where selenium content of soil and therefore Selenium intake is very low. Selenium deficiency leads to Keshan disease characterised by enlarged and poor heart function $(18,19)$. It has been seen in areas where dietary intake is less than $19 \mu \mathrm{g}$ per day for men and less than $13 \mu \mathrm{g}$ for women(20).

Selenium deficiency also appears to enhance the virulence or progression of some viral infections- e.g., there appears to be a unique interaction between selenium and HIV. Declining selenium levels in HIVinfected individuals are sensitive markers of disease progression and severity, even before malnutrition becomes a factor(21). Low levels of plasma selenium have also been associated with a significantly increased risk of death from HIV. Adequate selenium nutritional states may enhance resistance to HIV infection by enhancing functions of $\mathrm{T}$ helper cells and modifying their production of intracellular messengers known as cytokines(21). In HIV infection, increased oxidative stress appears to favour viral replication, possibly by activating specific transcription pathways. As an integral component of glutathione peroxidase and thrioredoxin reductase, selenium plays an impact role therefore decreasing oxidation stress in HIV infested cells and possibly suppressing the rate of HIV replication(22).It is therefore very worrisome that in the face of marked increase in HIV / AIDS cases in the country, intake of selenium among the population that is classified among the affluent in the society should be so low.

Although selenium is required for health, high dosage can be toxic. Symptoms of toxicity include alopecia (loss of hair), loss of nails, fatigue, nausea, vomiting and sour milk breath(13).

Frequency of food consumption : The frequency at which the different foods were eaten is shown in table 5. The figures show that, based on consumption pattern of >one/day ( $>1 / \mathrm{D})$, the most commonly consumed foodstuffs are vegetables (Onion, tomatoes), cereals and cereal product (rice, bread). Most of other foods listed were consumed three to six days in a week. Traditionally, selenium is obtained from seafoods, most cereals, vegetables and meat, such as beef and pork(17), while copper is most abundant in organ meats, shellfish, nuts and seeds, wheat bran, cereals and whole grain products(10). The present work also showed that plant products were richer sources of copper and selenium than animal and animal products. In conclusion, the dietary intake of selenium and copper by the students was poor and unacceptable especially in the case of selenium. There is a need to carry out assessment of blood levels and take remedial actions if deficiency and/or excess are indicated.

\section{ACKNOWLEDGEMENTS}

To the Director and staff of the ECOLAB, University of Ghana, Legon, for their technical assistance

\section{REFERENCES}

1. Johnson, H. L. and Sayberlich, H. E. Trace element analysis in biological samples. Clinical, Biochemical and Nutritional Aspects of Trace Elements (Ed. AS. Prad) pp. 405 - 426, Alan Liss Inc., New York, U.S.A, 1982.

2. Wolf, W. R. Trace elements in food. Clinical, Biochemical and Nutritional Aspects of Trace Elements (Ed. AS. Prad), 1982. pp.427-446, Alan Liss Inc. New York, U.S.A.

3. Underwood, E. J. Trace Elements in Human and Animal Nutritional, Academic Press, 1977, 4th edition p 1- 2.

4. Krause, M. V. and Mahan, L. K. Functions of micronutrients. In: Food, Nutrition and Diet Therapy, 6th edition, Saunders Co., Philadelphia, U.S.A. 1999; 129-132.

5. Holben, D. H. and Smith, A. M . The diverse role of selenium within selenoproteins: A review. J. Amer. Diet Ass. 1999; 99:836 - 843.

6. Mustaciach, D. and Powis, G. Thioredoxin reductase. Biochem J. 2000; 346:1- 8 .

7. Arthur, J. R The role of selenium in thyroid hormone metabolism. Can. J. Physiol. Pharm. 1991; 69:1648 - 1652

8. Lavender, O. A Nutrition and Newly emerging viral diseases. An overview. J. Nutr. 1997; 27:948 - 950.

9. Johnson, M. A. Is copper an antioxidant? Critical reviews in Food Science and Nutrition. 1992; 32:1-31.

10. Linder, M. C. and Hazegh - Azam, M. Copper biochemistry and molecular biology. Amer. J. Clin. Nutr. 1996; 63: 767-811. 
11. Takyi E. E. K. Nutritional status and Nutrient intake of pre-school children in Ghana. East Afr. Med. J. 1999; 76:508 - 513.

12. Turnlund, J. R. Copper In: Nutrition in Health and Disease $9^{\text {th }}$ edition (Ed. Shills, M et al). Baltimore: Williams and Wilkins. 1999;241-252.

13. Institute of Medicine. Food and Nutrition Board Dietary Reference Intakes: Vitamin C, Vitamin E, Selenium and Carotenoids. National Academy Press. Washington DC, USA, 2000.

14. Insttute of Medicine. Dietary reference intakes for vitamin A, vitamin K, boron, chromium, copper, iodine, manganese, molybdenum, nickel, silicon, vanadium and zinc. Washington DC. National Academy Press. 2001; 1-27.

15. Uauy, R. Essentiality of copper in humans. Am.J. Clin. Nutr. 1998; 67:9525-9595.

16. Conlan, D. Serum copper levels in elderly patients with femoral neck fracture Age and Ageing 1990; 19:212-214.

17. Robinson, M. F. Clinical effects of selenium deficiency and excess In: Clinical, Biochemistry and Nutritional Aspects of Trace Elements (Ed. Asa P.)1982 pp. 325 - 343, Alan Liss Inc. New York, USA.

18. Levander, O. A. and Beck, M. A. Interacting Nutritional and infectious etiologies in Keshan disease. Insight from Coxsackie virus B - induced myocardis in mice deficient in selenium or vitamin E. Biol. Trace Element Res. 1997; 56:5-21.

19. Levander, O. A. Nutrition and Newly emerging viral diseases. An overview. J. Nutr. 1997; 27:9485-9505.

20. Levander, O. A. Scientific rationale for the 1989 recommended dietary allowance for selenium. JAM Diet Association 1991; 91:1572-1576.

21. Banm, M. K selenium and Interleukins in persons infected with human immunodeficiency virus type 1. J. Inf. Dis. 2000; 182:569-573.

22. Look M. P. Serum selenium versus lymphocyte subset and markers of diseases progression and inflammatory response in human immunodeficiency virus -1 infection. Biological Trace Element Rg. 1997; 56:31-41. 